\title{
Whiteness and the Great Lie of Diversity
}

\author{
Mark Zunac
}

\section{All Diversity, All the Time}

Experts in sundry administrative offices within the edu-political complex have been promising that, by their continued and unrelenting efforts, the university will-still, eventually-become a paragon of inclusivity, tolerance, and humane learning. This will be done, we have been told, by labeling certain student populations "vulnerable" and by ensuring them a nebulously conceived safety from any thoughts, words, or ideas that might endanger their collective psyche. In announcing, for example, the rationale for a new mandatory diversity training program at the University of Wisconsin-Oshkosh, Chancellor Andy Leavitt bewailed a "lack of empathy . . . from a predominantly white, cisgender, heterosexual university community," whose members regularly commit "microaggressions in the classroom." Having heard his "students of diversity," Leavitt ensured his auditors that his training session will "encourage understanding" and "create a more fair and equitable climate for learning and employment." ${ }^{1}$ Targeting an entire community for its collective guilt in abstract thought-crimes would, one assumes, tend to aggravate any already existing schisms across various communities, but Leavitt knows this.

In truth, multicultural buzzwords like equity, inclusive excellence, and "lived experience" have become euphemisms for progressive activism and the transformation of universities into training grounds for brute-force leftism. There exists a growing body of research that indicates the broad failure of diversity training initiatives, but universities have only accelerated

1 Andrew Leavitt, "New, mandatory training to advance our commitment to diversity and inclusion," e-mail to all University of Wisconsin-Oshkosh employees, August 28, 2020. 
such efforts. ${ }^{2}$ Thus, in the face of sanguine promises that diversity training will translate into utopian fantasies of universal amity, universities are now characterized by resentment, suspicion, and a retrograde tribalism that actively works to undermine education.

When quainter ideations of diversity proved illusory, campus bureaucrats pivoted to a more militant form of identity politics, one in which safety and vulnerability were not only promoted as ideals, but were also presented as attainable only by a confrontation with a tangible, real-world scapegoat. Thereby whiteness and white supremacy became bywords for a reinvigorated diversity regime, one that, since demographics are destiny for the progressive mind, dispensed with tolerance, respect, and shared purpose in favor of the ideological subjugation that is in place today. Bellarmine University president Susan Donovan, in the fall of 2020, typified the attitude of higher-ed leadership when, after canceling classes over the Breonna Taylor case, counseled "white members of the community" to "recognize [their] part" in systemic racism, adding unironically that such a move will allow them to "work toward inclusion."3

\section{Diversity by Division}

An object lesson-one that evinces the pattern of the diversity movement on college campuses-might be taken from the University of Wisconsin-Madison. When it launched its "Madison Plan" in 1988 to address difficulties in recruiting and retaining minority students, its objectives were modest if uninspiring. A few, such as the promise to replace retiring faculty members with minority candidates "whenever possible," were harbingers of the desperations and ethical quandaries that hiring and admissions committees are faced with today.

Yet on the whole, the document is aware of the strains produced by both achieving the worthwhile goals of a pluralistic campus and fulfilling its responsibility as places of learning. For example, plans for the multicultural center placed a premium on academic success, even as they sought to promote

2 See, for example, Mike Noon, "Pointless Diversity Training: Unconscious Bias, New Racism, and Agency," Work, Employment, and Society 32, no. 1 (2018): 198-209; Edward Chang, et al., "The Mixed Effects of Online Diversity Training, PNAS 116, no. 16 (2019): 7778-83; Hans Bader, "How Diversity Training Widens the Gulf Among the Races," Minding the Campus, April 11, 2019.

3 Jackie Salo, "Bellarmine University Cancels Classes Amid Breonna Taylor Charges," New York Post, September 24, 2020. 
a "knowledge and appreciation of other cultures." There was ostensibly a genuine interest in the center's broad application to the campus community at large, something that could feasibly cultivate mutual understanding and social cohesion. In fact, "Domination of the center by any group or cluster of groups will doom the project." ${ }^{4}$ The center as it was thus constituted, however, became a site for the philosophical evolution of campus diversity and its correlative, multiculturalism.

Enter the new Diversity Framework, put into place at Madison in 2015 in order to create a safe and welcoming place for historically underrepresented groups. That campus bureaucrats felt the plan was needed was not of course a tacit admission that the Madison Plan had failed. As with most social engineering experiments, the experts simply concluded that the old plan was deficient only in the scope of resources needed for its complete success. It was also apparently too modest in its political and ideological goals.

Progressive social programs only accrete, and the Diversity Framework is an exemplar of ideology's persistence in the face of its own failures. Whereas just over thirty years ago the multicultural center represented a centralized, all-inclusive place, today the main concern for the administration is to coordinate the efforts of its multicultural hydra. This constellation of entities includes, but is not limited to, the Equity and Diversity Committees, Minority and Disadvantaged Coordinators, the Campus Climate and Diversity Committee, the Committee on Women in the University, LGBT Issues Committee, the Committee on Access and Accommodations in Instruction, and the Disabilities Accommodation Advisory Committee. In addition, it also reflects the subtly coercive nature of the diversity movement, conscripting all participants to "engage" with the diversity regime, even if, as we have seen, it conflicts with certain core tenets of intellectual endeavor. ${ }^{5}$

When bureaucrats seek to "incentivize" (initiative 14) behavior as a means to "standardizing" (initiative 12) a set of ideological precepts, as the Diversity Framework sets out to do, an enforcement apparatus will be assembled. What it amounts to is the proscription of any speech or conduct that offends members of favored groups, while also constructing the firm establishment

4 "The Madison Plan," February 9, 1988, https://diversity.wisc.edu/wp-content/uploads/2010/10/ Madison-Plan-1988.pdf., 19.

5 "Affecting R.E.E.L. Change for Diversity and Inclusion," May, 2015, https://diversity.wisc.edu/ wp-content/uploads/2017/04/Patricks-preferred-04.08.15-DF-REEL-Report-FINAL_Updated.pdf; see especially initiatives 5 and 12-16. 
of an oppressor-victim narrative, in which a claim of offense by an individual becomes a rallying cry for that victim's group. Gone is the Madison Plan's “firm commitment" to the protections afforded by the First Amendment, ${ }^{6}$ replaced by a "cultural competency program" implemented as a response to what the university's chair of the Hate and Bias Incident Team refers to as incidents of "disrespectful speech."

\section{The White Elephant in the Room}

Under the tendentious language of diversity and in the face of the elemental claim that race is socially constructed, individuals are now regularly marked and stigmatized according to that very construct. Administrators' worst suspicions about intolerance and systemic racism (or sexism, or genderism, or ableism) are validated by demonstrations of rage and expressions of the vulnerability they themselves orchestrate. As such, their work as progenitors of fairness and equity can proceed apace. Their business model is selfperpetuation, and they are all too glad to offer appeasement strategies to address grievances their programs have created.

This might also explain the staggering expansiveness of what now constitutes a "diverse" population. For the University of Wisconsin, it is now no longer confined to groups whose claims to systemic discrimination have historical roots, but also groups whose boutique identities allow them to appropriate such moral authority. These are now called "dimensions of diversity" and include not only race and ethnicity but also sex, gender, gender identity or expression, marital status, age, sexual orientation, and "affiliations that are based on cultural, political, religious, or other identities." ${ }^{8}$ The last classification is a nice touch, since it leaves open-ended the number of ways one might find oneself marginalized.

We do know, however, which groups do not qualify as a dimension of diversity, and herein lies the most obvious abrogation of the diversity covenant.

6 "The Madison Plan," 19, 21.

7 Will Hoverman, "UW Madison Prepares Cultural Competency Program for New Students," UW News, June 9, 2016, http://news.wisc.edu/uw-madison-prepares-cultural-competency-program-for-new-students/.

8 University of Wisconsin-Madison Ad Hoc Diversity Planning Committee, "Forward Together: A Framework for Diversity and Inclusive Excellence," May 19, 2014, https://diversity.wisc.edu/wp-content/uploads/2017/02/FrameworkforDiversityMay192014_2.pdf, 7. 
For group identities to accept and embrace their protected status, it has become imperative to let them know directly from whom, exactly, they are being protected. They are what education professor Penny Pasque refers to as "oppressor groups," who exist-and have throughout history existed-to exploit “target identities.” They are, alas, “people who are able-bodied, white, Christian, middle and upper-middle class, heterosexual men and those who have assimilated to US culture." 9

To summarize, in the name of equity and inclusivity, we are now labeling groups according to an intersectional hierarchy of righteousness, and we are told that this will ensure a peaceful coexistence in which tolerance, love, and mutual respect will win the day. Being white, and, to a lesser degree, male and heterosexual, is now an accusation, thereby making cyclical the dehumanizing features of racialized discourse. And, it is the natural culmination of our best diversity efforts. Experts deeply embedded in the higher education bureaucracy are naming names, and Maximilien Robespierre would not be prouder of this, our revolutionary moment.

9 Penny Pasque, American Higher Education, Leadership, and Policy: Critical Issues and the Public Good (New York: Palgrave Macmillan, 2010), 58. 